\title{
Sir William Richard Gowers (1845-1915) and his eponym
}

\author{
Yasemin Kaya • Levent Sarikcioglu
}

Received: 25 June 2014 / Accepted: 30 June 2014 / Published online: 12 July 2014

(C) Springer-Verlag Berlin Heidelberg 2014

Sir William Richard Gowers (1845-1915) made important contributions to the anatomy, physiology, and pathology of the nervous system. In 1865, Gowers embarked on his undergraduate career as a medical student at University College Hospital. Gowers' interest in diseases of the nervous system was probably due to the fact that some of his teachers and colleagues at University College Hospital, including John Russell Reynolds (1828-1896) and Henry Charlton Bastian (1837-1915) [1]. In 1870, he was appointed medical registrar to the National Hospital in Queen Square. In 1879, Gowers also wrote a seminal monograph on "Pseudo-hypertrophic muscular paralysis" (now known as Duchenne muscular dystrophy). Although he was not the first to describe the method utilized by children with Duchenne dystrophy to rise from the ground to a standing position, he provided clear illustrations of this phenomenon [2], which to this day is still frequently referred to as "Gowers' sign" (Fig. 1).

His textbook "A Manual of Diseases of the Nervous System" was the most monumental contribution to neurology and has rightfully been called the "bible" of neurology $[3,4]$. His monographs and lectures were based almost entirely on his own clinical observations meticulously recorded in shorthand [5]. He described methods to evaluate muscular strength, coordination, sensory perception, tone, tremor, reflexes and actions of individual muscles, and functions of cranial nerves.

In his last years of life, Gowers devoted himself to teaching, writing, and practicing neurology. At the age of 62 he was forced into retirement, feebled by "generalized cerebrovascular degeneration." Gowers survived with his wife Mary by just

Y. Kaya $\cdot$ L. Sarikcioglu $(\triangle)$

Department of Anatomy, Akdeniz University Faculty of Medicine, 07070 Antalya, Turkey

e-mail: levent@akdeniz.edu.tr

L. Sarikcioglu

e-mail: sarikcioglul@gmail.com
2 years and died on 4 May 1915. His funeral took place at St Peter's Church, Vere Street, in Kensington [6].

\section{His eponym}

Gowers' sign is a well-known neurological sign that indicates weakness of the muscles of the lower limb. It is a characteristic maneuver used by patients with weakness in proximal lower limb and trunk to rise from the ground. From the lying position, the patient rolls to the kneeling position, pushes on the ground with extended forearms to lift the hips, and straighten the legs, so forming a triangle with hips at the apex with hand and feet on the floor forming the base. Then the hands are used to push on the knees and so lift up the trunk ("climbing up oneself") [7] (Fig. 1 and cover image). In moderate cases, the prone crawl position and extension of all four extremities is used [8].

\section{Historical origin}

He described several methods to examine muscular strength, coordination, sensory perception, tone, tremor, reflexes, and actions of individual muscles in his textbook. Gowers included some methods to evaluate the functions of cranial nerves. In 1879, Gowers first described the pattern of standing in 21 boys with pseudohypertrophic muscular paralysis in a clinical lecture to the students of University College [9].

The sign was originally described by Gowers in the context of Duchenne muscular dystrophy. Gowers was not the first to describe the sign; Sir Charles Bell had reported it almost 50 years before Gowers' account [7]. There are three Gowers' signs: pain along the compressed sciatic nerve on passive dorsiflexion of the foot; the irregular contraction of the pupil 
Fig. 1 Cover image. Gowers' sign. Adoption of the patient from prone position to stand up was sketched

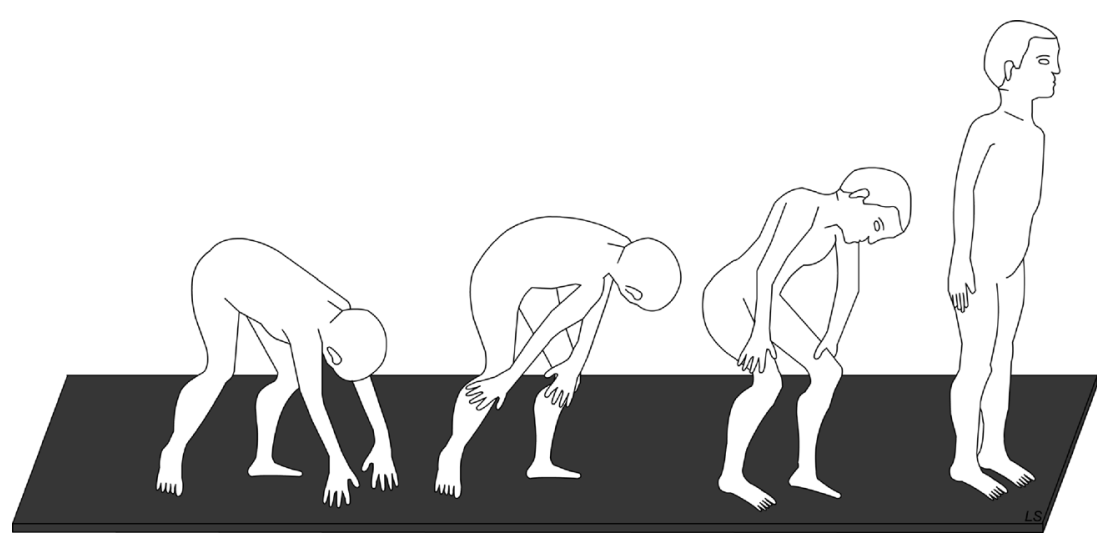

in early tabes (cf. Argyll Robertson); and the climbing up the legs signs in Duchenne dystrophy [10].

Although Gowers inveighed about of the use of eponyms, best known eponyms that bears his name are Gowers' phenomenon, Gowers' distal myopathy, Gowers' solution in the treatment of migraine, Gowers' anterior spinocerebellar tract, and Gowers' sign [10]. He also made contributions to other branches of neurology including neuromuscular diseases, neuro-ophthalmology, and spinal cord diseases [5]. He is probably best remembered for his most monumental contribution to the neurology. His "Manual of Diseases of the Nervous System" initially appeared in 1886-1888, followed by a second edition in 1892-1893, and a partial third edition in 1899 [3].

\section{Pathophysiology of Gowers' sign}

In description of the Gowers' sign, two important features have been emphasized: (1) the children adopting a prone position on all fours before attempting to stand and (2) the children "walking up their legs." It is the second feature that is often quoted in neurology textbooks as Gowers' sign [9].

The most important feature of the Gowers' sign is adoption of a prone position before standing. Children who had a positive Gowers' sign almost universally turned prone first in rising from a supine position to standing up [8]. This position reduces the forces required for knee extension and typical co-activation of multiple muscle groups in the rising action. While knee extension, hamstring muscles also make contraction to maximize knee extension. The upper extremities' position of abduction and extension further helps to complete hip extension. Wide hip abduction compensates for gluteus medius and minimus weakness by producing a wide base as normal balance and stability are compromised. Anterior pelvic tilt, lumbar hyperlordosis, and upper limb extension are used to compensate for a weak gluteus maximus muscle. In severe cases, hand supports on the floor and thigh travel less distance, secondary to a weaker shoulder girdle, knee extensors, and hip extensors. Heel contracture and equines posturing often are evident, but also serve to improve the knee extension moment. However, when the equine becomes too severe or when hip and/or knee flexion contractures develop, the patient cannot arise without an external support of a chair or wall [8]. This is why the patients use their hand to push on the knees and so lift up the trunk ("climbing up oneself') [7].

\section{Associations of Gowers' sign}

Gowers' sign is a nonspecific sign and, as with other tests of muscle strength in children with arthritis, it may be possible that the arthritis itself causes the difficulty in rising from the floor. Gower's sign is a screening test and can be seen with various conditions that is associated with proximal muscle weakness, including but not limited to, Becker's muscular dystrophy, limb girdle and other muscular dystrophies, proximal ascending pseudomyopathic diseases, spinal muscular atrophy, sarcoglycanopathy, polymyositides, discitis, and juvenile idiopathic arthritis [8]. It is also used in testing paraplegia.

Conflict of interest The authors declare no conflict of interest.

\section{References}

1. Holmes G (1951) Sir William Gowers at the National Hospital. Br Med J 2(4744):1397-1399

2. Gowers WR (1879) Pseudo-hypertrophic muscular paralysis. J \& A. Churchill, London

3. Tyler KL (2003) William Richard Gowers (1845-1915). J Neurol 250(8):1012-1013. doi:10.1007/s00415-003-1154-5

4. Tyler KL, McHenry LC Jr (1983) Classics in neurology. Fragments of neurologic history: pseudohypertrophic muscular dystrophy and Gowers' sign. Neurology 33(1):88-89 
5. Vale TC, Lees A, Cardoso F (2013) A biosketch of William Richard Gowers with a new review of his inpatient case history notes. Arq Neuropsiquiatr 71(6):411-413. doi:10.1590/0004-282X20130049

6. Vale TC, Glass PG, Lees A, Cardoso F (2013) Gowers' Queen Square case notes on chorea: a 21 st century re-appraisal. Eur Neurol 69(1):48-52. doi:10.1159/000343628

7. Larner AJ (2011) A dictionary of neurological signs, 3rd edn. Springer, New York
8. Chang RF, Mubarak SJ (2012) Pathomechanics of Gowers' sign: a video analysis of a spectrum of Gowers' maneuvers. Clin Orthop Relat Res 470(7):1987-1991. doi:10.1007/s11999011-2210-6

9. Wallace GB, Newton RW (1989) Gowers' sign revisited. Arch Dis Child 64(9):1317-1319

10. Pearce JM (2000) Gowers' sign. J Neurol Neurosurg Psychiatry 68(2):149 